Check for updates

Cite this: RSC Adv., 2019, 9, 10520

Received 19th December 2018

Accepted 27th March 2019

DOI: $10.1039 / c 8 r a 10386 k$

rsc.li/rsc-advances

\section{Atomic-scale investigation of the heterogeneous structure and ionic distribution in an ionic liquid using scanning transmission electron microscopy}

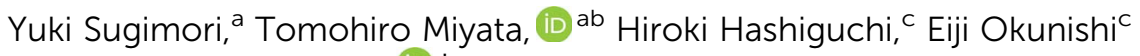 \\ and Teruyasu Mizoguchi (D) *a
}

\begin{abstract}
Ionic liquids show characteristic properties derived from them being composed of only molecular ions, and have recently been used as solvents for chemical reactions and as electrolytes for electrochemical devices. The liquid structures, i.e., ionic distributions, form when solutes are dissolved in ionic liquids and fundamentally affect the reactions and transfer efficiency in such solutions. In this study, we directly observe the liquid structure in a solution of the long-chain ionic liquid 1-octyl-3-methylimidazolium bromide $\left(\mathrm{C}_{8} \mathrm{mim} \mathrm{Br}\right)$ and barium stearate $\left(\mathrm{Ba}\left(\mathrm{C}_{17} \mathrm{H}_{35} \mathrm{COO}\right)_{2}\right)$ using the annular dark-field method of scanning transmission electron microscopy (ADF-STEM). The ADF image shows a $10 \mathrm{~nm}$-scale heterogeneity in the image intensity, which reflects the heterogeneous ionic distribution in the solution. The number density distributions of all the component ions $\left(\mathrm{C}_{8} \mathrm{mim}^{+}, \mathrm{Br}^{-}, \mathrm{Ba}^{2+}\right.$, and $\left.\mathrm{C}_{17} \mathrm{H}_{35} \mathrm{COO}^{-}\right)$were estimated from the ADF image intensity and then visualized. These ionic distribution maps depicted the spatial relationships between the ions at the sub-nanometer scale and revealed that the heterogeneity is largely derived from the large differences in size, charge distributions, and van der Waals interactions.
\end{abstract}

\section{Introduction}

Ionic liquids have attracted great attention as new solvents and media for absorption, separation, chemical reactions, ionic transfer, and other applications..$^{1-6}$ For instance, cellulose dissolution and $\mathrm{CO}_{2}$ capture in ionic liquids have been extensively studied, and their use as electrolytes in batteries has been considered based on their high ionic density. ${ }^{1,3,4,7-12}$

Ionic liquids are composed of at least two charged species (a cation and an anion), and in many cases, these ions have charged and neutral portions in their molecular structures. Owing to these molecular structures, ionic liquids can show properties similar to those of either inorganic molten salts or molecular liquids, or intermediate between them.

Furthermore, small angle scattering and molecular dynamics simulations have indicated that ionic liquids with long sidechains form nanoscale domain structures due to the aggregation of the ionic portions and the non-ionic sidechains of neighbouring molecules. ${ }^{13,14}$ In dilute solutions, solutes are reported to be preferentially solvated in specific domains of domain-forming ionic liquids. ${ }^{15}$ On the other hand, in concentrated solutions, the interaction between the solute and

${ }^{a}$ Institute of Industrial Science, The University of Tokyo, 4-6-1 Komaba, Meguro, Tokyo 153-8505, Japan. E-mail: teru@iis.u-tokyo.ac.jp

${ }^{b}$ Institute of Multidisciplinary Research for Advanced Materials, Tohoku University, 21-1, Katahira, Aoba, Sendai, Miyagi 980-8577, Japan

'JEOL Ltd., 3-1-2, Musashino, Akishima, Tokyo 196-8558, Japan solvent may change the liquid structure; in other words, the solute and solvent may cooperatively form a new liquid structure different from that of the dilute solution. The solution structure could deform drastically depending on the charge, polarity, size, and structure of the solute and solvent molecules. In turn, the liquid structures and the solute/solvent distribution determine the solubility, relative positions, collision frequency, and mobility of the reactive and catalytic molecules, which affect the efficiency of chemical reaction and ionic transfer.

However, the local liquid structures and local heterogeneity of ionic liquids, which are formed at the sub-nanometer scale, have not yet been revealed due to the lack of high-spatialresolution real-space analysis methods. Recently, the authors achieved the visualization of individual atoms in an ionic liquid using atomic-resolution scanning transmission electron microscopy (STEM) ${ }^{16,17}$ Annular dark-field (ADF) imaging using STEM has atomic-number $(Z)$ sensitivity, which enables the identification of atomic species, ${ }^{18,19}$ and thus has the potential to identify the positions of the solute and solvent molecules in solution.

In this study, we apply atomic-resolution ADF-STEM for investigating the local liquid structure, i.e., the local distribution of the solute and solvent ions, in an ionic liquid solution. Barium stearate is dissolved in the ionic liquid 1-octyl-3methylimidazolium bromide $\left(\mathrm{C}_{8} \mathrm{mimBr}\right)$; thus, four types of ions $\left(\mathrm{C}_{8} \mathrm{mim}^{+}, \mathrm{Br}^{-}, \mathrm{Ba}^{2+}\right.$, and $\left.\mathrm{C}_{17} \mathrm{H}_{35} \mathrm{COO}^{-}\right)$are present in the solution. The ionic distributions of all the constituent ions are estimated from the ADF image by resolving the relational 
expressions for the ADF image intensities, densities, and thicknesses of the respective ionic components. This manuscript aims to directly identify the spatial correlations between the constituent ions, and moreover, to discuss the origin of the heterogeneous ionic distribution based on the molecular structures of the ions.

\section{Experiment}

\section{(i) Specimen preparation}

We utilized the ionic liquid $\mathrm{C}_{8} \operatorname{mimBr}$ (Kanto Chemical Co. Inc., purity: $99 \%)$ as the solvent and barium stearate $\left(\mathrm{Ba}\left(\mathrm{C}_{17} \mathrm{H}_{35^{-}}\right.\right.$ $\mathrm{COO}_{2}$ ) (FUJIFILM Wako Pure Chemical Corporation, purity: $95 \%)$ as the solute. We selected these materials because they have so large atomic numbers $(\mathrm{Br}, Z=35$ and $\mathrm{Ba}, Z=56)$ that they are expected to be observed brightly by ADF-STEM. Moreover, $\mathrm{Br}$ and $\mathrm{Ba}$ are expected to be distinguished in an ADFimage owing to the difference of their atomic numbers. Furthermore, structural heterogeneities are expected to be observed owing to each different length of long alkyl chain in $\mathrm{C}_{8} \mathrm{mimBr}$ and barium stearate. Their molecular structures are shown in Fig. 1. First, barium stearate was dissolved in $\mathrm{C}_{8} \mathrm{mimBr}$ at a ratio of $0.015 \mathrm{M}$. Then, a mixture of the ionic liquid solution and ethanol was dropped onto a Quantifoil R1.2/ 1.3 holey carbon film (Quantifoil GmbH). Finally, the specimen was heated under vacuum to evaporate the ethanol and form freestanding thin films of the ionic liquid solution in the carbon film holes. Ionic liquids are generally nonvolatile; thus, these liquid films could be observed by TEM without solid sealing films. Further details are given in the previous report. ${ }^{20}$

\section{(ii) STEM observation and image simulation}

We observed the ultrathin liquid film using an aberrationcorrected scanning transmission electron microscope (JEMARM200F NEOARM, JEOL Ltd.) equipped with a cold-type field-emission gun. The accelerating voltage was set to 200 $\mathrm{kV}$. The beam current was $\sim 10 \mathrm{pA}$, and the probe diameter was $\sim 0.08 \mathrm{~nm}$. The probe-forming aperture half-angle and the detection half-angle for the bright-field (BF) and ADF images were set to $18.5,0-11 \mathrm{mrad}$, and $45-180 \mathrm{mrad}$, respectively. The dwell time was $40 \mu$ s per pixel, and the total acquisition time for an image was $41.9 \mathrm{~s}$. All the experimental images were smoothed by a simple moving average filter of 5 $\times 5$ pixels. The sample thickness was estimated by the electron energy-loss spectroscopy log-ratio method. ${ }^{21}$ The thickness of the the specimens shown in Fig. 2(a, c) and (b, d) were measured to be approximately 9 and $6.5 \mathrm{~nm}$, respectively. The ADF-image simulations were performed using the multi-slice method (Dr. Probe package). ${ }^{22}$

\section{(iii) Spatial distribution analysis of $\mathrm{Ba}^{2+}$}

The spatial distribution of $\mathrm{Ba}^{2+}$ was determined using the average nearest-neighbour distance analysis. The distance to the nearest-neighbour for each point was averaged for all the points. Then, the averaged value was compared to the expected (a)

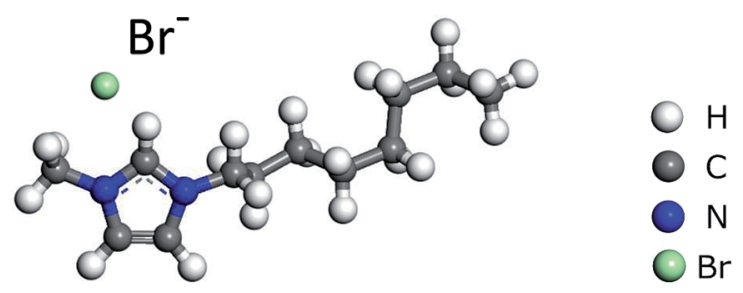

$\mathrm{C}_{8} \operatorname{mimBr}$

(b)

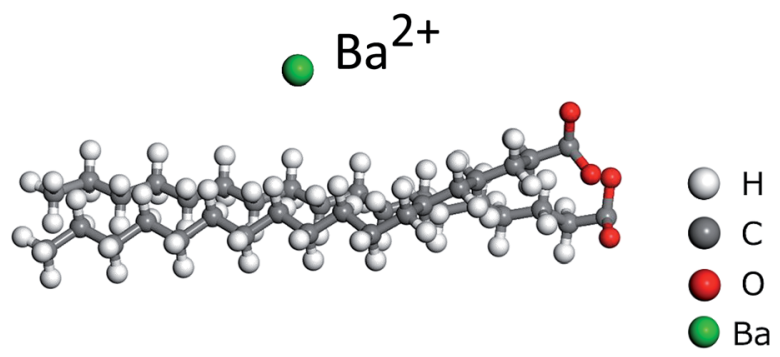

Barium stearate

$\left(\mathrm{Ba}\left(\mathrm{C}_{17} \mathrm{H}_{35} \mathrm{COO}\right)_{2}\right)$

Fig. 1 Molecular structures of (a) 1-octyle-3-methylimidazolium bromide $\left(\mathrm{C}_{8} \mathrm{mimBr}\right)$ and $(\mathrm{b})$ barium stearate.

value, and the standard deviation obtained under the random distribution. ${ }^{23}$

\section{(iv) Spatial distribution mapping of the constituent ions}

The spatial mapping was performed as follows. First, coarsegrained processing (binning of $11 \times 11$ pixels, $0.82 \mathrm{~nm}$ per pixel) was applied to Fig. 3(a) to obtain Fig. 3(b). The number distribution of the solute cation $\mathrm{Ba}^{2+}$ was extracted by determining the positions of the very bright spots. Then, the distributions of the other constituent ions $\left(\mathrm{Br}^{-}, \mathrm{C}_{8} \mathrm{mim}^{+}\right.$, and $\mathrm{C}_{17} \mathrm{H}_{35} \mathrm{COO}^{-}$) were also estimated. Diagrammatic illustrations are shown in Fig. 3(c).

First, the ADF intensities of the constituent atoms, molecules, and molecular pairs were estimated using the ADF image simulations:

$$
\begin{gathered}
I_{\mathrm{H}}=0.05 I_{\mathrm{C}}, I_{\mathrm{N}}=1.80 I_{\mathrm{C}}, I_{\mathrm{O}}=2.34 I_{\mathrm{C}}, I_{\mathrm{Br}}=33.70 I_{\mathrm{C}}, I_{\mathrm{Ba}}=66.47 I_{\mathrm{C}} \\
I_{\mathrm{C}_{8} \operatorname{mim}}=16.77 I_{\mathrm{C}}, I_{\mathrm{C}_{17} \mathrm{COO}}=24.47 I_{\mathrm{C}} \\
I_{\mathrm{BaBr}_{2}}=(66.47+2 \times 33.70) I_{\mathrm{C}}=133.87 I_{\mathrm{C}}, \\
I_{\left[\mathrm{C}_{8} \operatorname{mim}\right] \mathrm{Br}}=(16.77+33.70) I_{\mathrm{C}}=50.47 I_{\mathrm{C}} \\
I_{\left[\mathrm{C}_{8} \operatorname{mim}\right]\left[\mathrm{C}_{17} \mathrm{COO}\right]}=(16.77+24.47) I_{\mathrm{C}}=41.24 I_{\mathrm{C}},
\end{gathered}
$$



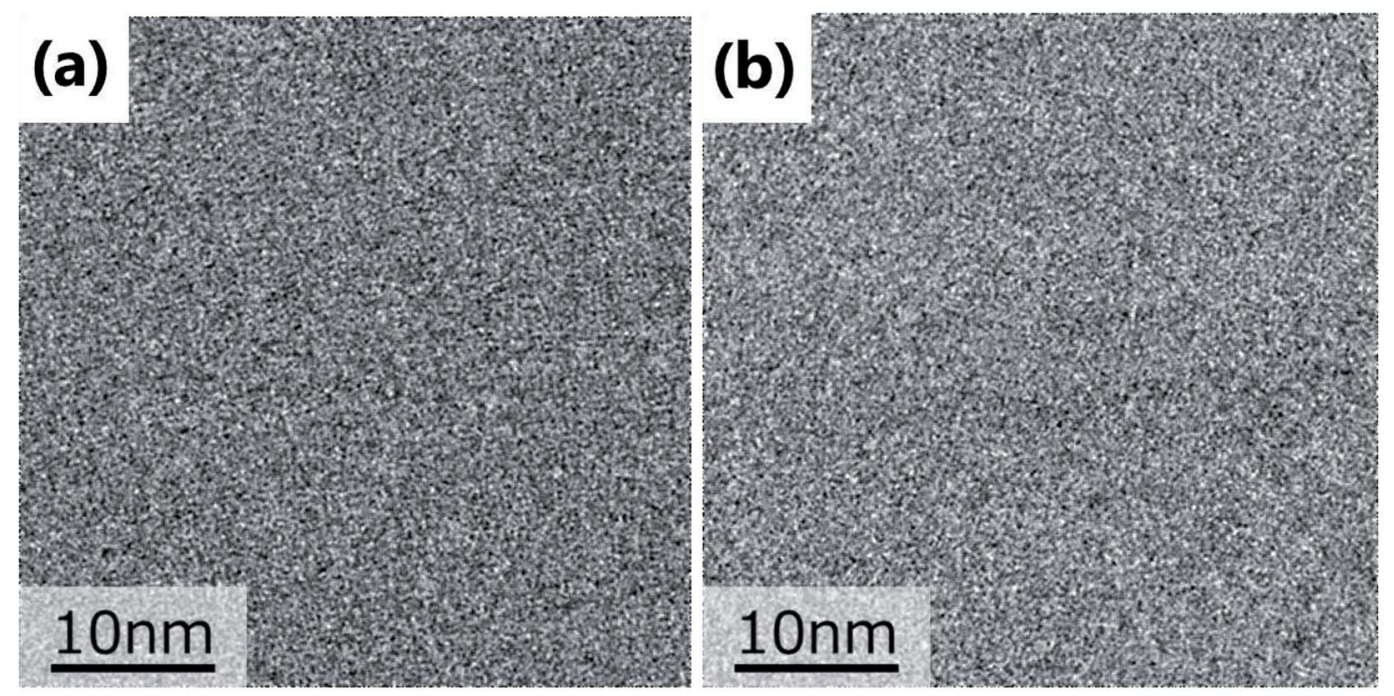

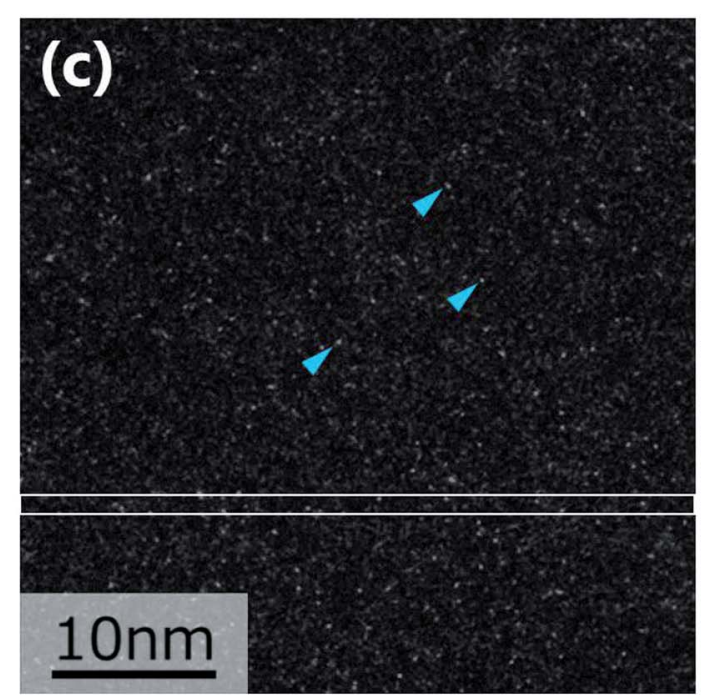

(e)

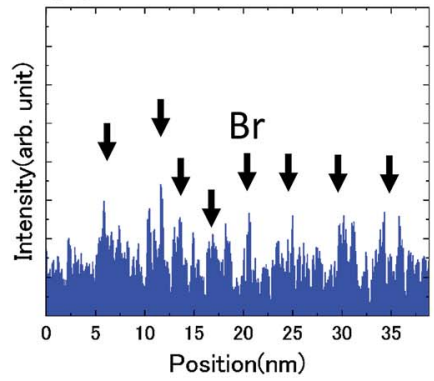

(f)

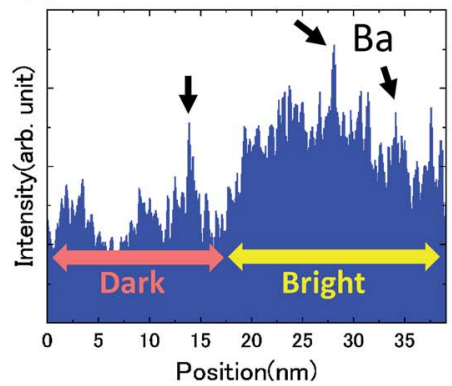

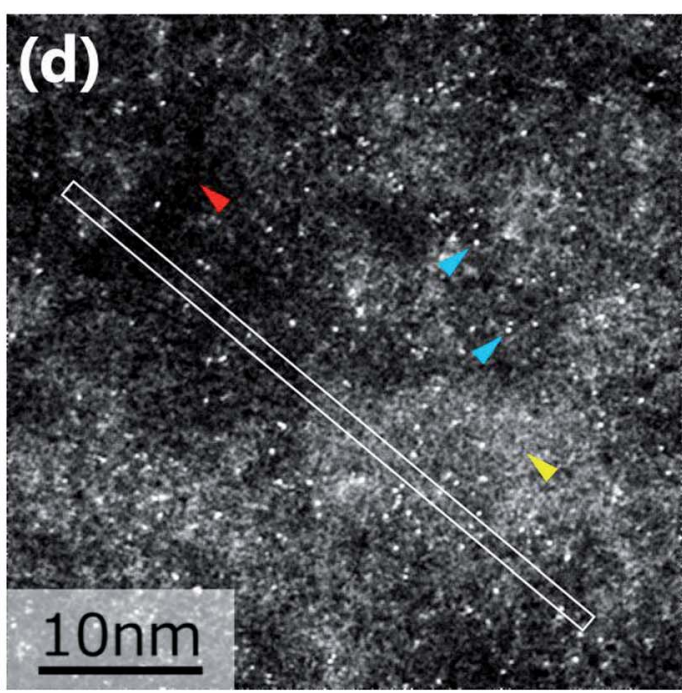

(g)

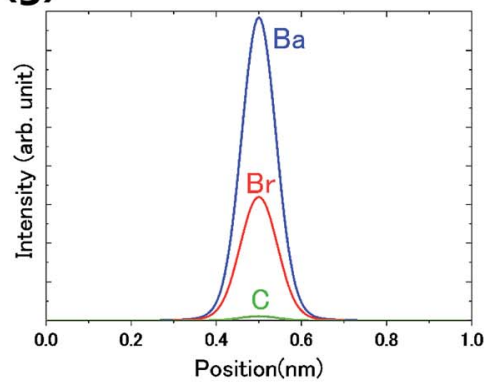

Fig. 2 (a), (b) BF and (c), (d) ADF images of non-doped and solute-doped $\mathrm{C}_{8}$ mimBr. (e) and (f) Intensity profiles along the lines in (c) and (d). (g) Simulated $\mathrm{ADF}$ intensity profiles of $\mathrm{C}, \mathrm{Br}$ and $\mathrm{Ba}$ atoms in a vacuum.

where $I_{\mathrm{H}}, I_{\mathrm{C}}, I_{\mathrm{N}}, I_{\mathrm{O}}, I_{\mathrm{Br}}$, and $I_{\mathrm{Ba}}$ are the integrated intensities of an atom of hydrogen, carbon, nitrogen, oxygen, bromine, and barium, respectively (C, Br, and Ba are shown in Fig. $2(\mathrm{~g})$ ). The experimental $I_{\mathrm{Ba}}$ was estimated from the integrated intensity of a bright spot of $\mathrm{Ba}^{2+}$ in the ADF image, and then $I_{\mathrm{C}}$ was calculated using the expression above. $I_{\mathrm{C}_{8} \operatorname{mim}}$ and $I_{\mathrm{C}_{17} \mathrm{COO}}$ are the intensities of $\mathrm{C}_{8} \mathrm{mim}^{+}$and $\mathrm{C}_{17} \mathrm{H}_{35} \mathrm{COO}^{-}$ions, respectively, which were estimated by summing up the constituent atoms. $I_{\left[\mathrm{C}_{8} \mathrm{mim}\right] \mathrm{Br}}, I_{\left[\mathrm{C}_{8} \mathrm{mim}\right]\left[\mathrm{C}_{17} \mathrm{COO}\right]}$, and $I_{\mathrm{BaBr}_{2}}$ are the integrated intensities of the ion pairs $\mathrm{C}_{8} \mathrm{mim}^{+}$and $\mathrm{Br}^{-}, \mathrm{C}_{8} \mathrm{mim}^{+}$and $\mathrm{C}_{17} \mathrm{H}_{35} \mathrm{COO}^{-}$, and $\mathrm{Ba}^{2+}$ and two $\mathrm{Br}^{-}$, respectively.

Based on the intensity relationships, we described the pixel intensities in the ADF image. The liquid film thickness was approximately separated into three layers of the ionic pairs: $\mathrm{Ba}^{2+}$ 

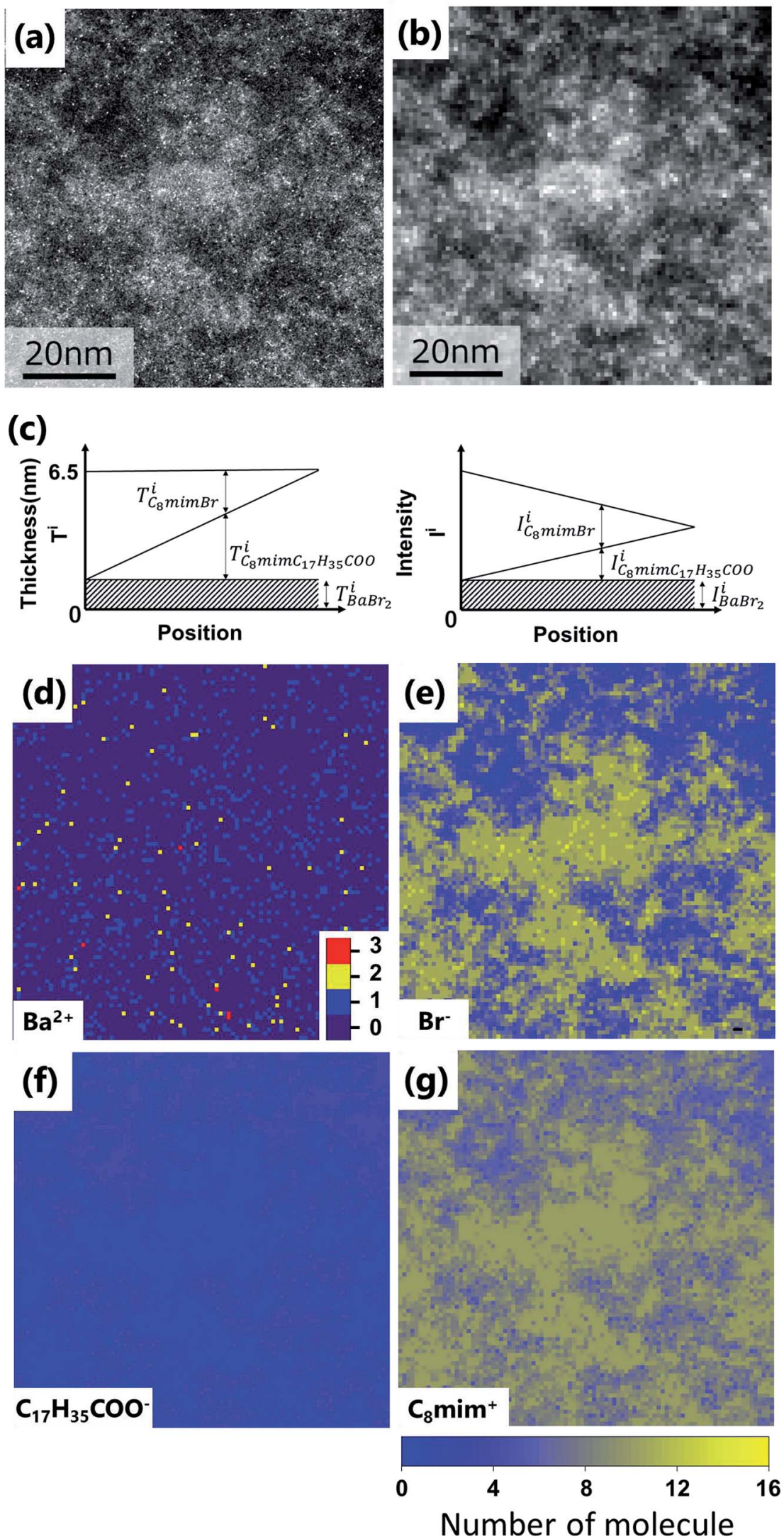

Fig. 3 (a) Original images of Fig. 2(d). Fig. 2(d) is the upper left corner of this image. (b) Coarse-grained image from (a) by averaging $11 \times 11$ pixels $(0.82 \mathrm{~nm}$ per pixel). (c) Thickness (left) and intensity (right) diagrams of the respective components for estimating the ionic distributions. (d-g) Estimated spatial distributions of $\mathrm{Ba}^{2+}, \mathrm{Br}^{-}, \mathrm{C}_{17} \mathrm{H}_{35} \mathrm{COO}^{-}$, and $\mathrm{C}_{8} \mathrm{mim}^{+}$, respectively. 
and two $\mathrm{Br}^{-}, \mathrm{C}_{8} \mathrm{mim}^{+}$and $\mathrm{Br}^{-}$, and $\mathrm{C}_{8} \mathrm{mim}^{+}$and $\mathrm{C}_{17} \mathrm{H}_{35} \mathrm{COO}^{-}$. The intensities of the separated layers were estimated with the following equations:

$$
\begin{aligned}
& I_{\mathrm{BaBr}_{2}}^{\mathrm{i}}=A_{\text {pix }} \times T_{\mathrm{BaBr}_{2}}^{\mathrm{i}} \times \rho_{\mathrm{BaBr}_{2}} \times I_{\mathrm{BaBr}_{2}} \\
& I_{\left[\mathrm{C}_{8} \operatorname{mim}\right] \mathrm{Br}}^{\mathrm{i}}=A_{\text {pix }} \times T_{\left[\mathrm{C}_{8} \operatorname{mim}\right] \mathrm{Br}}^{\mathrm{i}} \times \rho_{\left[\mathrm{C}_{8} \operatorname{mim}\right] \mathrm{Br}} \times I_{\left[\mathrm{C}_{8} \operatorname{mim}\right] \mathrm{Br}} \\
& I_{\left[\mathrm{C}_{8} \operatorname{mim}\right]\left[\mathrm{C}_{17} \mathrm{COO}\right]}^{\mathrm{i}}=A_{\mathrm{pix}} \times T_{\left[\mathrm{C}_{8} \operatorname{mim}\right]\left[\mathrm{C}_{17} \mathrm{COO}\right]}^{\mathrm{i}} \times \rho_{\left[\mathrm{C}_{8} \operatorname{mim}\right]\left[\mathrm{C}_{17} \mathrm{COO}\right]} \\
& \times I_{\left[\mathrm{C}_{8} \operatorname{mim}\right]\left[\mathrm{C}_{17} \mathrm{COO}\right]}
\end{aligned}
$$

where $A_{\text {pix }}$ is the area of a coarse-grained pixel, $0.68 \mathrm{~nm}^{2}$. The densities were: $\rho_{\mathrm{BaBr}_{2}}=9.68 \mathrm{~nm}^{-3}\left(\mathrm{BaBr}_{2}\right.$ (ref. 24)), $\rho_{\left[\mathrm{C}_{8} \mathrm{mim}\right] \mathrm{Br}}=$ $2.55 \mathrm{~nm}^{-3}$ (pure $\mathrm{C}_{8} \mathrm{mimBr}^{25}$ ), and $\rho_{\left[\mathrm{C}_{8} \operatorname{mim}\right]\left[\mathrm{C}_{17} \mathrm{COO}\right]}=1.12 \mathrm{~nm}^{-3}$ (estimated from ref. 26). The thickness was assumed to be constant over the whole image $(T=6.5 \mathrm{~nm})$.

$$
T=T_{\mathrm{BaBr}_{2}}^{\mathrm{i}}+T_{\left[\mathrm{C}_{8} \operatorname{mim}\right] \mathrm{Br}}^{\mathrm{i}}+T_{[\mathrm{C} 8 \operatorname{mim}]\left[\mathrm{C}_{17} \mathrm{COO}\right]}^{\mathrm{i}}=6.5(\mathrm{~nm})
$$

Because the number of $\mathrm{Br}^{-}$anions is much larger than that of $\mathrm{C}_{17} \mathrm{H}_{35} \mathrm{COO}^{-}$anions, $\mathrm{Ba}^{2+}$ was assumed to be solvated with $\mathrm{Br}^{-}\left(\mathrm{BaBr}_{2}\right)$ for a simple consideration. The total intensity at pixel $\mathrm{i}$ is described as follows:

$$
\begin{aligned}
I^{\mathrm{i}}= & I_{\mathrm{BaBr}_{2}}^{\mathrm{i}}+I_{\left[\mathrm{C}_{8} \operatorname{mim}\right] \mathrm{Br}}^{\mathrm{i}}+I_{\left[\mathrm{C}_{8} \operatorname{mim}\right]\left[\mathrm{C}_{17} \mathrm{COO}\right]}^{\mathrm{i}} \\
= & \left(117 T_{\mathrm{BaBr}_{2}}^{\mathrm{i}} \rho_{\mathrm{BaBr}_{2}}+40 T_{\left[\mathrm{C}_{8} \operatorname{mim}\right] \mathrm{Br}}^{\mathrm{i}} \rho_{\left[\mathrm{C}_{8} \operatorname{mim}\right] \mathrm{Br}}\right. \\
& \left.+34 T_{\left[\mathrm{C}_{8} \operatorname{mim}\right]\left[\mathrm{C}_{17} \mathrm{COO}\right]}^{\mathrm{i}} \rho_{\left[\mathrm{C}_{8} \operatorname{mim}\right]\left[\mathrm{C}_{17} \mathrm{COO}\right]}\right) A_{\mathrm{pix}} \times I_{\mathrm{C}}
\end{aligned}
$$

Here, the thickness of the $\mathrm{BaBr}_{2}$ layer, $T_{\mathrm{BaBr}_{2}}^{\mathrm{i}}$, can be estimated from the number of $\mathrm{Ba}^{2+}$ cations, $N_{\mathrm{Ba}}^{\mathrm{i}}\left(=N_{\mathrm{BaBr}_{2}}\right)$, which has already been obtained, with the equation: $T_{\mathrm{BaBr}_{2}}^{\mathrm{i}}=N_{\mathrm{Ba}}^{\mathrm{i}} /\left(A_{\text {pix }} \times \rho_{\mathrm{BaBr}_{2}}\right)$. Thus, the equations about the intensities and thickness can be resolved to obtain the thickness of the components $T_{\left[\mathrm{C}_{8} \mathrm{mim}\right] \mathrm{Br}}^{\mathrm{i}}$ and $T_{\left[\mathrm{C}_{8} \mathrm{mim}\right]\left[\mathrm{C}_{17} \mathrm{COO}\right]}^{\mathrm{i}}$; these values in turn can be used to give the number of ionic pairs in pixel i,

$$
\begin{gathered}
N_{\left[\mathrm{C}_{8} \text { mim }\right] \mathrm{Br}}^{\mathrm{i}}=A_{\text {pix }} \times T_{\left[\mathrm{C}_{8} \operatorname{mim}\right] \mathrm{Br}}^{\mathrm{i}} \times \rho_{\left[\mathrm{C}_{8} \operatorname{mim}\right] \mathrm{Br}} \\
N_{\left[\mathrm{C}_{8} \operatorname{mim}\right]\left[C_{17} \mathrm{COO}\right]}^{\mathrm{i}}=A_{\text {pix }} \times T_{\left[\mathrm{C}_{8} \operatorname{mim}\right]\left[\mathrm{C}_{17} \mathrm{COO}\right]}^{\mathrm{i}} \times \rho_{\left[\mathrm{C}_{8} \operatorname{mim}\right]\left[\mathrm{C}_{17} \mathrm{COO}\right]}
\end{gathered}
$$

Finally, the numbers of the respective constituent ions in pixel i can be derived:

$$
\begin{gathered}
N_{\mathrm{Ba}}^{\mathrm{i}}\left(=N_{\mathrm{BaBr}_{2}}^{\mathrm{i}}\right)(\text { extracted directly }), N_{\mathrm{Br}}^{\mathrm{i}}=2 N_{\mathrm{BaBr}_{2}}^{\mathrm{i}}+N_{\left[\mathrm{C}_{8} \operatorname{mim}\right] \mathrm{Br}}^{\mathrm{i}} \\
N_{\mathrm{C}_{8} \operatorname{mim}}^{\mathrm{i}}=N_{\left[\mathrm{C}_{8} \operatorname{mim}\right] \mathrm{Br}}^{\mathrm{i}}+N_{\left[\mathrm{C}_{8} \operatorname{mim}\right]\left[\mathrm{CH}_{17} \mathrm{COO}\right]}^{\mathrm{i}}, \\
N_{\mathrm{C}_{17} \mathrm{COO}}^{\mathrm{i}}=N_{\left[\mathrm{C}_{8} \operatorname{mim}\right]\left[\mathrm{CH}_{17} \mathrm{COO}\right]}^{\mathrm{i}}
\end{gathered}
$$

The equations fulfill local electrical neutrality:

$$
2 N_{\mathrm{Ba}}^{\mathrm{i}}+N_{\mathrm{C}_{8} \operatorname{mim}}^{\mathrm{i}}=N_{\mathrm{Br}}^{\mathrm{i}}+N_{\mathrm{C}_{17} \mathrm{COO}}^{\mathrm{i}}
$$

\section{(v) Relationships between the numbers of ions}

The number of $\mathrm{C}_{8} \mathrm{mim}^{+}$and $\mathrm{Br}^{-}$ions were averaged around the pixels containing $\mathrm{C}_{17} \mathrm{H}_{35} \mathrm{COO}^{-}$, as discussed later. In the same way, the average number of $\mathrm{C}_{8} \mathrm{mim}^{+}$and $\mathrm{C}_{17} \mathrm{H}_{35} \mathrm{COO}^{-}$ions were graphed against the number of $\mathrm{Br}^{-}$ions. $\mathrm{Ba}^{2+}$ ions were not plotted here because their number was too small, statistically.

To analyse the relationships between the distribution of $\mathrm{Ba}^{2+}$ and the other ions, the number of $\mathrm{Br}^{-}, \mathrm{C}_{8} \mathrm{mim}^{+}$, and $\mathrm{C}_{17} \mathrm{H}_{35} \mathrm{COO}^{-}$ions in the 8 pixels surrounding $\mathrm{Ba}^{2+}$ were averaged. The Pauling's ionic radii of $\mathrm{Ba}^{2+}$ and $\mathrm{Br}^{-}$are 0.135 and $0.195 \mathrm{~nm} ;{ }^{27}$ thus, the size of $\mathrm{BaBr}_{2}$ or pairs of $\mathrm{Ba}^{2+}$ and the ions with sidechains should be greater than $1.050 \mathrm{~nm}$, which is larger than the coarse-grained pixel size of $0.82 \mathrm{~nm}$. In addition, $\mathrm{Ba}^{2+}$ is not necessarily at the centre of the pixel. Thus, the surrounding pixels should be considered. The average numbers of $\mathrm{Br}^{-}$and the ions with sidechains around the pixels with and without $\mathrm{Ba}^{2+}$ are plotted in Fig. 5(b).

\section{Results and discussion}

\section{(i) Comparison of the non-doped and solute-doped $\mathrm{C}_{8} \operatorname{mimBr}$}

Fig. 2(a)-(d) show the BF and ADF images of the non-doped and solute (barium stearate)-doped $\mathrm{C}_{8} \mathrm{mimBr}$. Neither of the $\mathrm{BF}$ images shows characteristic contrast, indicating that the samples were in amorphous states (Fig. 2(a) and (b)). On the other hand, clear bright/dark contrast is observed in the ADF images (Fig. 2(c) and (d)). The ADF image intensity directly corresponds to the positions of the atoms, with the heavier atoms having much higher intensities. That is, the intensity contrast in the ADF image directly corresponds to the liquid structure. The intensity profiles along the lines in the ADF images are shown in Fig. 2(e) and (f).

The ADF image of the non-doped specimen $\left(\mathrm{C}_{8} \mathrm{mimBr}\right.$ only) shows many bright spots (Fig. 2(c)), which were assumed to be $\mathrm{Br}^{-}$ions because the atomic number of $\mathrm{Br}\left(Z_{\mathrm{Br}}=35\right)$ is much larger than those of the other components $(Z \leqq 7)$. While the $\mathrm{Br}^{-}$positions exhibited a higher intensity in the image than the others, the local mean intensity was almost constant over the entire image, indicating that the distribution of $\mathrm{Br}^{-}$did not exhibit any large heterogeneities (Fig. 2(e)).

On the other hand, the ADF image of the solute-doped specimen shows three distinguishable levels of contrast, namely, very bright spots (blue arrows), bright regions (yellow arrow), and dark regions (red arrow) (Fig. 2(d) and (f)). The sizes of the bright and dark regions were both measured to be approximately $10 \mathrm{~nm}$.

\section{(ii) Analysis of the ionic distributions}

The intensity ratio of the clearest peaks among the very bright spots in Fig. 2(d) and the bright spots in Fig. 2(c) was around 2, indicating that the very bright spots in the solute-doped specimen were derived from an element much heavier than $\mathrm{Br}$. In the present solution, the solute cation $\mathrm{Ba}^{2+}$ has a larger atomic 
number $(Z=56)$ than the other atoms $\left(Z_{\mathrm{H}}=1, Z_{\mathrm{C}}=6, Z_{\mathrm{N}}=7\right.$, $\left.Z_{\mathrm{O}}=8, Z_{\mathrm{Br}}=35\right)$. Fig. $2(\mathrm{~g})$ shows the simulated ADF intensity of the individual $\mathrm{C}, \mathrm{Br}$, and $\mathrm{Ba}$ atoms in a vacuum. The intensity ratio of $\mathrm{Ba}$ to $\mathrm{Br}\left(I_{\mathrm{Ba}} / I_{\mathrm{Br}}\right)$ was estimated to be 1.97 , which is almost identical to the ratio measured in the experimental images. In other words, the very bright spots in the solutedoped specimens are the solute cation $\mathrm{Ba}^{2+}$.

Next, we focused on the bright and dark regions in the image. The ADF image intensity is determined by the thickness, density, and composition, and the thickness of the liquid film was considered to be approximately equal in the local areas observed here due to the surface tension. Thus, this image would display the heterogeneity of the density and composition, i.e. the ionic distribution.

Subsequently, the number distributions of the ions $\mathrm{Ba}^{2+}$, $\mathrm{Br}^{-}, \mathrm{C}_{8} \mathrm{mim}^{+}$, and $\mathrm{C}_{17} \mathrm{H}_{35} \mathrm{COO}^{-}$) estimated in the experiment section are displayed in Fig. 3(d)-(g).

First, $\mathrm{Ba}^{2+}$ seems to be dispersed rather than aggregated (Fig. 3(d)), but the average nearest neighbour analysis indicates that it has a $91 \%$ probability of exhibiting a concentrated distribution. The $\mathrm{Br}^{-}$distribution in Fig. 3(e) is similar to the original ADF image of Fig. 3(a), because the high intensity of $\mathrm{Br}$ $\left(I_{\mathrm{Br}}\right)$ contributes to the ADF image much more than $\mathrm{C}_{8} \mathrm{mim}^{+}$and $\mathrm{C}_{17} \mathrm{H}_{35} \mathrm{COO}^{-}$. Based on the figure, the $\mathrm{Br}^{-}$distribution shows large heterogeneity; $\mathrm{Br}^{-}$-rich and $\mathrm{Br}^{-}$-poor regions are formed at a scale of $10 \mathrm{~nm}$. On the other hand, $\mathrm{C}_{17} \mathrm{H}_{35} \mathrm{COO}^{-}$shows the opposite contrast to the ADF image; that is, more $\mathrm{C}_{17} \mathrm{H}_{35} \mathrm{COO}^{-}$ is observed in the $\mathrm{Br}^{-}$-poor regions (Fig. 3(f), (e) and 4). This indicates that the anions $\mathrm{Br}^{-}$and $\mathrm{C}_{17} \mathrm{H}_{35} \mathrm{COO}^{-}$are less miscible to each other in the solution.

Finally, Fig. $3(\mathrm{~g})$ shows the $\mathrm{C}_{8} \mathrm{mim}^{+}$distribution, which is similar to but more widely spread than that of $\mathrm{Br}^{-}$. This can be ascribed to the amount of the $\mathrm{C}_{8} \mathrm{mim}^{+}$. Namely, the amount of $\mathrm{C}_{8} \mathrm{mim}^{+}$is much larger than that of $\mathrm{Ba}^{2+}$, thus $\mathrm{C}_{8} \mathrm{mim}^{+}$is mainly used to compensate the negative charges of both $\mathrm{Br}^{-}$and $\mathrm{C}_{17} \mathrm{H}_{35} \mathrm{COO}^{-}$. Furthermore, by carefully observing the distribution of $\mathrm{C}_{17} \mathrm{H}_{35} \mathrm{COO}^{-}$(Fig. 3(f)), it is found that $\mathrm{C}_{17} \mathrm{H}_{35} \mathrm{COO}^{-}$ does not have strong trend to bind with $\mathrm{C}_{8} \mathrm{mim}^{+}$. This trend can be clearly seen in Fig. 4(a) and (b). The amount of $\mathrm{C}_{8} \mathrm{mim}^{+}$has proportional relationship to that of $\mathrm{Br}^{-}$(Fig. 4(a)), whereas it is inverse proportional to that of $\mathrm{C}_{17} \mathrm{H}_{35} \mathrm{COO}^{-}$(Fig. 4(b)). This point will be discussed later.

To clearly know the relationships among the ionic distributions, the average numbers of the ions were plotted against the number of $\mathrm{C}_{17} \mathrm{H}_{35} \mathrm{COO}^{-}$and $\mathrm{Br}^{-}$ions in Fig. 4(a) and (b), respectively. The numbers of $\mathrm{Br}^{-}$and $\mathrm{C}_{17} \mathrm{H}_{35} \mathrm{COO}^{-}$show an inverse proportional relationship because they are both negatively charged. On the other hand, Fig. 4(a) shows the linear increase of the number of $\mathrm{C}_{8} \mathrm{mim}^{+}$ions against that of $\mathrm{Br}^{-}$to compensate the negative charge. The number of $\mathrm{C}_{8} \mathrm{mim}^{+}$ions has inverse proportional to that of $\mathrm{C}_{17} \mathrm{H}_{35} \mathrm{COO}^{-}$. This can be simply ascribed to the Coulomb interaction between molecules/ ions, that is $\mathrm{Br}^{-}$attracts $\mathrm{C}_{8} \mathrm{mim}^{+}$ions than the $\mathrm{C}_{17} \mathrm{H}_{35} \mathrm{COO}^{-}$ions.

On the other hand, such simple explanation cannot be applied to the relationships between $\mathrm{C}_{8} \mathrm{mim}^{+}$and $\mathrm{C}_{17} \mathrm{H}_{35} \mathrm{COO}^{-}$. As can be seen in Fig. 4(b), the number of $\mathrm{C}_{8} \mathrm{mim}^{+}$decreases by increasing the number of $\mathrm{C}_{17} \mathrm{H}_{35} \mathrm{COO}^{-}$even though they should (a)

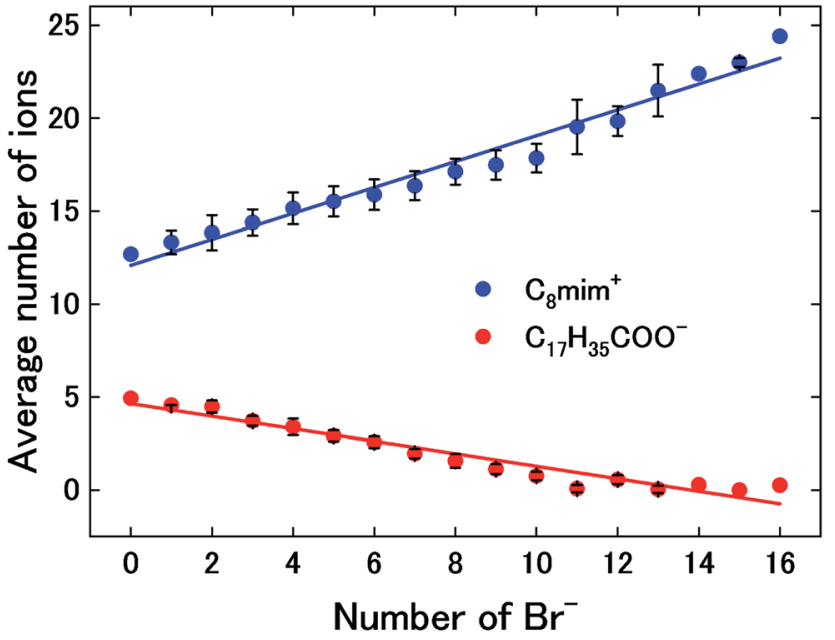

(b)

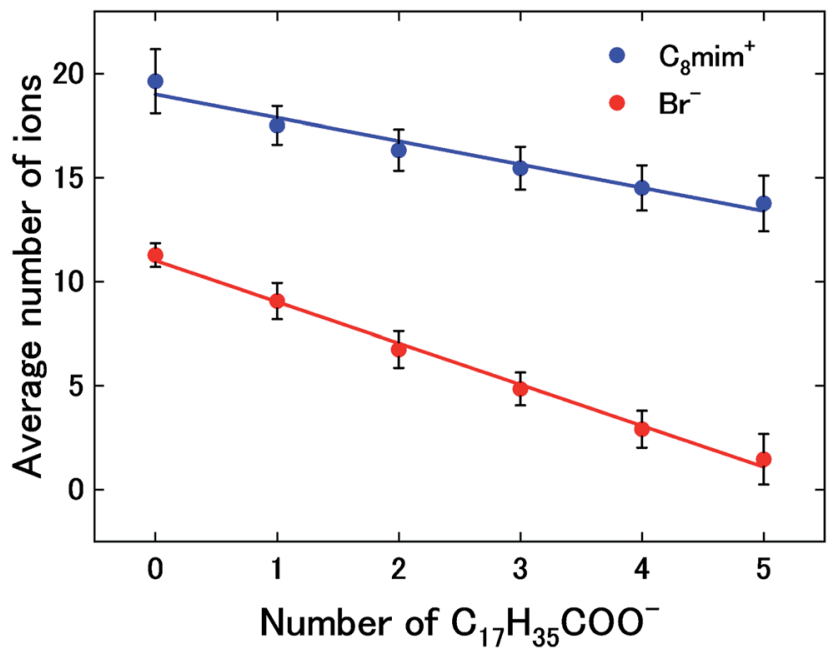

Fig. 4 Graphs of (a) the average number of $\mathrm{C}_{8} \mathrm{mim}^{+}$and $\mathrm{C}_{17} \mathrm{H}_{35} \mathrm{COO}^{-}$ ions against the number of $\mathrm{Br}^{-}$ions and (b) the average number of $\mathrm{Br}^{-}$ and $\mathrm{C}_{8} \mathrm{mim}^{+}$ions against the number of $\mathrm{C}_{17} \mathrm{H}_{35} \mathrm{COO}^{-}$ions.

have attractive Coulomb interaction. This can be ascribed to the long alkali chain and weak ionicity of both molecules.

Next, the $\mathrm{Ba}^{2+}$ distribution in the liquid was investigated. In Fig. 5(a), the number density of $\mathrm{Ba}^{2+}$ (colored) is overlaid on that of $\mathrm{Br}^{-}$(black-white). Based on this figure, $\mathrm{Ba}^{2+}$ is mainly distributed in the $\mathrm{Br}^{-}$-rich regions. Here, we analysed the relationships between the average number of $\mathrm{Br}$ - ions and those of the ions with sidechains $\left(\mathrm{C}_{8} \mathrm{mim}^{+}\right.$and $\left.\mathrm{C}_{17} \mathrm{H}_{35} \mathrm{COO}^{-}\right)$at pixels with and without $\mathrm{Ba}^{2+}$. The graph in Fig. 5(b) shows that the number of $\mathrm{Br}^{-}$ions increases where $\mathrm{Ba}^{2+}$ is present, while the number of ions with sidechains decreases. This tendency would be caused by the stronger attractive Coulomb interaction between $\mathrm{Ba}^{2+}$ and $\mathrm{Br}^{-}$.

\section{(iii) Discussion of the heterogeneous ionic distributions}

We now discuss the reason why such a $10 \mathrm{~nm}$-scale heterogeneous structure was formed in the present specimen. On the 

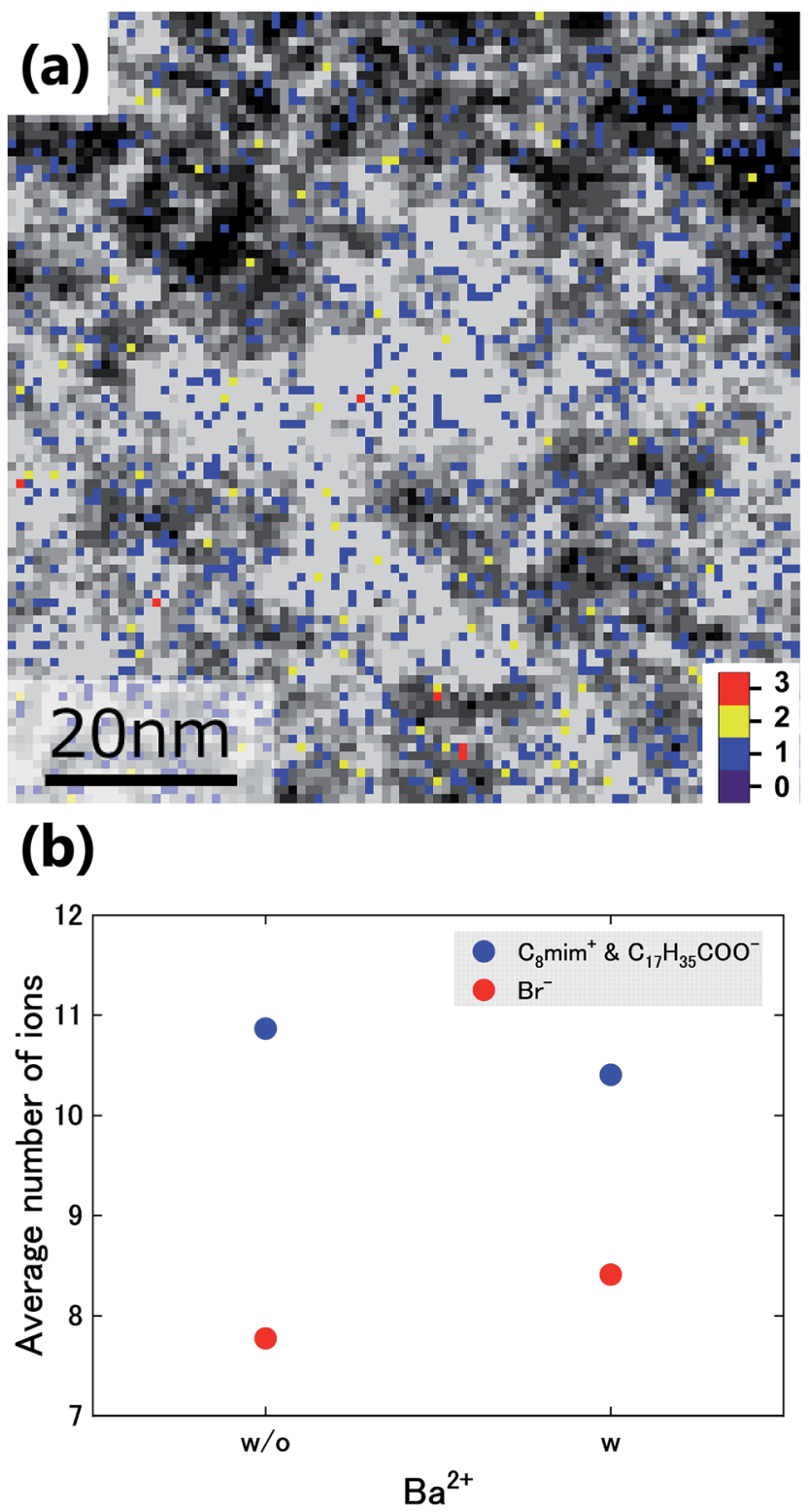

Fig. 5 (a) Overlay of the images in Fig. 3(d) and (e). (b) Average number of $\mathrm{Br}^{-}$ions and of the ions with sidechains $\left(\mathrm{C}_{8} \mathrm{mim}^{+}\right.$and $\left.\mathrm{C}_{17} \mathrm{H}_{35} \mathrm{COO}^{-}\right)$ around the pixels with (w) and without (w/o) $\mathrm{Ba}^{2+}$.

other hand, based on the small angle X-ray scattering, the structural heterogeneities of ionic liquids containing $\mathrm{C}_{8} \mathrm{mim}^{+}$ were reported to be approximately $2 \mathrm{~nm}^{13,28}$ The $2 \mathrm{~nm}$ scale heterogeneity is found in our non-doped $\mathrm{C}_{8} \mathrm{mimBr}$ (Fig. 2(c)), but it is much smaller than the Ba-stearate doped specimen (Fig. 2(d)). So, the formation of the large heterogeneity can be ascribed to the Ba-stearate doping.

The small and multivalent ions $\left(\mathrm{Ba}^{2+}\right.$ and $\left.\mathrm{Br}^{-}\right)$are known to show large Coulomb interactions, whereas the molecular ions with delocalized ionic portions and long noncharged sidechains $\left(\mathrm{C}_{8} \mathrm{mim}^{+}\right.$and $\left.\mathrm{C}_{17} \mathrm{H}_{35} \mathrm{COO}^{-}\right)$have weaker ionic interactions than the charged ions, and instead show attractive van der Waals (vdW) interactions between the sidechains. ${ }^{27}$ These phenomena may account for the results: $\mathrm{C}_{17} \mathrm{H}_{35} \mathrm{COO}^{-}$ions aggregate with each other due to the strong vdW interactions between the very long alkyl chains, $\mathrm{Br}^{-}$ions gather separately from the $\mathrm{C}_{17} \mathrm{H}_{35} \mathrm{COO}^{-}$aggregate regions, and $\mathrm{Ba}^{2+}$ is likely to be located in $\mathrm{Br}^{-}$-rich regions. The main factor of the heterogeneous liquid structure would thus be the long alkyl chain of $\mathrm{C}_{17} \mathrm{H}_{35} \mathrm{COO}^{-}$, whereas the small contributions of the cations $\mathrm{Ba}^{2+}$ to the liquid structure might be caused by the low concentration and small size of $\mathrm{Ba}^{2+}$ ion.

This study revealed that, while ionic liquids with two components (a cation and an anion) such as $\mathrm{C}_{8}$ mimBr show homogeneous distributions, those with four components (two cations and two anions) can exhibit heterogeneous ionic distributions originating from the preferential ionic aggregation and separation, which occurs because the interactions among the ions differ depending on the combinations and relative configurations of the ions. In addition, this study has demonstrated the potential of visualizing the spatial distributions of up to four types of ions in ionic liquids using thin specimens and ADFSTEM observation; this method will help in understanding the nanoscale heterogeneity in ionic liquids and designing ionic liquid solutions for effective solvents and transfer media.

\section{Conclusions}

To understand the solute- and solvent-ion distributions and liquid structures in a solution composed of the long-chain ionic liquid $\mathrm{C}_{8} \mathrm{mimBr}$ and the surfactant barium stearate, atomicresolution ADF-STEM observation was utilized. The ADF image of the thin liquid film of the solution shows a $10 \mathrm{~nm}$-scale heterogeneity in its intensity, with bright and dark regions that are attributed to the heterogeneous distribution of the constituent ions in the solution. The spatial distribution of the solute cation $\mathrm{Ba}^{2+}$, solvent anion $\mathrm{Br}^{-}$, solvent cation $\mathrm{C}_{8} \mathrm{mim}^{+}$and solute anion $\mathrm{C}_{17} \mathrm{H}_{35} \mathrm{COO}^{-}$were identified by image processing and the relationships of the ADF intensities, densities, and thicknesses of the constituent ions.

Concerning the heterogeneity of the molecule/ion distributions, $\mathrm{Br}^{-}$and $\mathrm{C}_{17} \mathrm{H}_{35} \mathrm{COO}^{-}$show strong heterogeneity while the heterogeneity is weaker in $\mathrm{Ba}^{2+}$ and $\mathrm{C}_{8} \mathrm{mim}^{+}$. The heterogeneous structure can mainly be attributed to the long alkyl chain of $\mathrm{C}_{17} \mathrm{H}_{35} \mathrm{COO}^{-}$, which would create strong vdW interactions between sidechains.

This paper has demonstrated the direct visualization of the heterogeneous structure and their forming mechanisms via the atomic-resolution ADF-STEM. Our method would strongly support the elucidation and development of ionic liquid solutions from the microscopic perspective.

\section{Conflicts of interest}

There are no conflicts to declare.

\section{Acknowledgements}

The STEM measurements were conducted at JEOL Ltd. This study was supported by the Mitsubishi Science Foundation (27143), Grants-in-Aid for Scientific Research from Ministry of Education, Culture, Sports, Science and Technology (MEXT) (no. 25106003, 26630302, 26249092, and JP17H06094), and the 
Japan Science and Technology Agency (JST)-Precursory Research for Embryonic Science and Technology (PRESTO) (JPMJPR16NB 16814592).

\section{Notes and references}

1 M. Armand, F. Endres, D. R. MacFarlane, H. Ohno and B. Scrosati, Nat. Mater., 2009, 8, 621-629.

2 Z. Lei, B. Chen, Y. M. Koo and D. R. Macfarlane, Chem. Rev., 2017, 117, 6633-6635.

3 Y. Yamada, K. Usui, K. Sodeyama, S. Ko, Y. Tateyama and A. Yamada, Nat. Energy, 2016, 1, 1-9.

4 M. C. Lin, M. Gong, B. Lu, Y. Wu, D. Y. Wang, M. Guan, M. Angell, C. Chen, J. Yang, B. J. Hwang and H. Dai, Nature, 2015, 520, 325-328.

5 M. Semsarilar and S. Perrier, Nat. Chem., 2010, 2, 811-820.

6 M. Asadi, K. Kim, C. Liu, A. V. Addepalli, P. Abbasi, P. Yasaei, P. Phillips, A. Behranginia, J. M. Cerrato, R. Haasch, P. Zapol, B. Kumar, R. F. Klie, J. Abiade, L. A. Curtiss and A. SalehiKhojin, Science, 2016, 353, 467-470.

7 R. P. Swatloski, S. K. Spear, J. D. Holbrey and R. D. Rogers, J. Am. Chem. Soc., 2002, 124, 4974-4975.

8 C. Cadena, J. L. Anthony, J. K. Shah, T. I. Morrow, J. F. Brennecke and E. J. Maginn, J. Am. Chem. Soc., 2004, 126, 5300-5308.

9 H. Zhang, J. Wu, J. Zhang and J. He, Macromolecules, 2005, 38, 8272-8277.

10 E.-K. Shin and B.-C. Lee, J. Chem. Eng. Data, 2008, 53, 27282734.

11 M. Klähn and A. Seduraman, J. Phys. Chem. B, 2015, 119, 10066-10078.

12 J. L. Anderson, J. N. K. Dixon, E. J. Maginn and J. F. Brennecke, J. Phys. Chem. B, 2006, 110, 15059-15062.
13 A. Triolo, O. Russina, H.-J. Bleif and E. Di Cola, J. Phys. Chem. $B, 2007,111,4641-4644$.

14 J. N. A. Canongia Lopes and A. A. H. Pádua, J. Phys. Chem. B, 2006, 110, 3330-3335.

15 K. Fruchey and M. D. Fayer, J. Phys. Chem. B, 2010, 114, 28402845.

16 T. Miyata, F. Uesugi and T. Mizoguchi, Sci. Adv., 2016, 3, e1701546.

17 T. Miyata and T. Mizoguchi, Microscopy, 2018, 67, i162-i167.

18 T. Mizoguchi, S. D. Findlay, A. Masuno, Y. Saito, K. Yamaguchi, H. Inoue and Y. Ikuhara, ACS Nano, 2013, 7, 5058-5063.

19 P. D. Nellist and S. J. Pennycook, Ultramicroscopy, 1999, 78, 111-124.

20 T. Miyata and T. Mizoguchi, Ultramicroscopy, 2017, 178, 8187.

21 T. Malis, S. C. Cheng and R. F. Egerton, J. Electron Microsc. Tech., 1988, 8, 193-200.

22 J. Barthel, Ultramicroscopy, 2018, 193, 1-11.

23 P. J. Clark and F. C. Evans, Ecology, 1954, 35, 445-453.

24 Z. Yan, G. Gundiah, G. A. Bizarri, E. C. Samulon, S. E. Derenzo and E. D. Bourret-Courchesne, Nucl. Instrum. Methods Phys. Res., Sect. A, 2014, 735, 83-87.

25 C. Kolbeck, J. Lehmann, K. R. J. Lovelock, T. Cremer, N. Paape, P. Wasserscheid, A. P. Fröba, F. Maier and H. P. Steinrück, J. Phys. Chem. B, 2010, 114, 17025-17036.

26 C. Ye and J. M. Shreeve, J. Phys. Chem. A, 2007, 111, 14561461.

27 R. D. Shannon, Acta Crystallogr., 1976, 751.

28 O. Russina, A. Triolo, L. Gontrani, R. Caminiti, D. Xiao, L. G. Hines, R. A. Bartsch, E. L. Quitevis, N. Plechkova and K. R. Seddon, J. Phys.: Condens. Matter, 2009, 21, 424121. 